
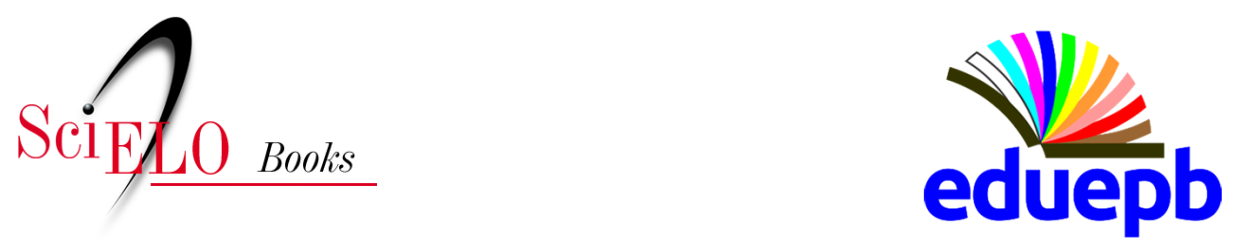

\title{
Magnetismo e Condução de Calor no Trabalho de Seebeck \\ Desafios da Ciência Experimental
}

\author{
Ana Paula Bispo da Silva
}

\section{SciELO Books / SciELO Livros / SciELO Libros}

SILVA, A. P. B. Magnetismo e Condução de Calor no Trabalho de Seebeck: Desafios da Ciência Experimental. In: SILVA, A. P. B., and MOURA, B. A., eds. Objetivos humanísticos, conteúdos científicos: contribuições da história e da filosofia da Ciência para o ensino de Ciências [online]. Campina Grande: EDUEPB, 2019, pp. 53-88.

ISBN: 978-85-78795-79-5. http://doi.org/10.7476/9786586221664.0003.

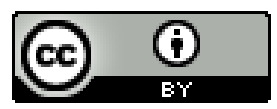

All the contents of this work, except where otherwise noted, is licensed under a Creative Commons Attribution 4.0 International license.

Todo o conteúdo deste trabalho, exceto quando houver ressalva, é publicado sob a licença Creative Commons Atribição 4.0.

Todo el contenido de esta obra, excepto donde se indique lo contrario, está bajo licencia de la licencia Creative Commons Reconocimento 4.0. 


\title{
MAGNETISMO E CONDUÇÃO DE CALOR NO TRABALHO DE SEEBECK: DESAFIOS DA CIÊNCIA EXPERIMENTAL
}

\author{
Ana Paula Bispo da Silva \\ Universidade Estadual da Paraíba (UEPB) \\ anabispouepb@gmail.com
}

\section{Introdução}

D esquisas envolvendo a história da ciência e o ensino de ciências incluem o uso de experimentos como parte da apren-

1 dizagem por investigação (ou problematização). De forma complementar à discussão sobre natureza da ciência, experimentos baseados em estudos de caso históricos permitiriam também o desenvolvimento de competências procedimentais e habilidades argumentativas. Isto porque considera-se que experimentos e instrumentos históricos representam contextos que vão além da ciência, e trazem de forma explícita ou implícita, representações sociais, culturais e materiais de um determinado período. Ainda, procedimentos experimentais correspondem a mudanças na própria forma de se pensar a ciência e foram se alterando ao longo da história da ciência (SHAPIN, 1982; JARDIM; GUERRA, 2017).

Questões associadas a equipamentos, precisão, exatidão, modelos, etc., interferiram no modo de "experimentar" sobre a ciência. Se durante o século 17 os experimentos e equipamentos tinham como principal função imitar um fenômeno observado na natureza; a partir do século 18 , quando a eletricidade e o magnetismo começam a ser estudados mais profundamente, experimentos e instrumentos passam a ser "criados". A partir do 
século 19, experimentos e instrumentos representam mais teorias e modelos preexistentes do que a própria natureza (HEERING; HÖTTECKE, 2014).

Abordar as mudanças pelas quais o modo de fazer ciência passou, bem como seus procedimentos, faz parte das recomendações para o ensino de ciências. É a partir do conhecimento destas mudanças, ou seja, da abordagem histórica, que se torna possível discutir a não linearidade e não neutralidade da ciência e rever visões sobre o método e o conhecimento científico (CACHAPUZ et al., 2011). Entretanto, assim como outras metodologias no ensino de ciências, a abordagem histórica ainda precisa lidar com algumas dificuldades. Uma delas está relacionada a uma interpretação inadequada dada a estudos de caso históricos. $\mathrm{O}$ uso de narrativas históricas lineares e aproblemáticas, mesmo quando envolvem experimentos, reforçam uma visão positivista e indutivista da ciência. Por esta visão, a abordagem histórica não contribui para o reconhecimento da ciência como um conhecimento complexo, mas antes enfatiza sua falsa superioridade e neutralidade (HÖTTECKE; SILVA, 2011).

Um suposto modo de contribuir para a aprendizagem da ciência a partir da abordagem histórica seria associando aspectos da natureza da ciência aos conceitos teóricos e práticas experimentais. Desta forma, a história da ciência não seria utilizada apenas como ilustrativa ou como pretexto, mas faria parte do próprio conteúdo curricular, explicitando conceitos, procedimentos e atitudes que se pretende abordar em sala de aula. Se características do trabalho científico, como modelos matemáticos e teóricos e hipóteses teóricas e experimentais fossem explicitadas nas narrativas históricas utilizadas em sala de aula, talvez houvesse menor rejeição à utilização da abordagem histórica por parte dos professores. Conforme apontam Höttecke e Silva (2011), um dos obstáculos para os professores utilizarem a abordagem histórica em sala de aula é o fato dela não conter a dificuldade esperada das ciências exatas, nem tampouco sua exatidão. 
A utilização de estudos de casos históricos, teóricos ou experimentais, em que não há uma solução correta a encontrar, é uma possibilidade para remediar essa situação, inserindo elementos investigativos nas aulas de ciências. As possíveis montagens e testes seriam planejadas e executadas pelos estudantes, discutindo e interagindo entre si, em busca de um consenso. Como prevê a aprendizagem por investigação (CARVALHO, 2013), esse tipo de atividade permite desenvolver várias competências entre os estudantes, como argumentação e interpretações conceituais.

O século 19 possui muitos casos históricos que permitem esta abordagem, principalmente nos estudos relacionados à eletricidade, calor e magnetismo. Além disso, é nesse século que as consequências das duas revoluções, a industrial e a francesa, influenciam a ciência, criando novos interesses e classes sociais ligadas aos avanços tecnológicos e científicos (JARDIM; GUERRRA, 2017). Foi a partir do século 19 que braços da ciência, como eletricidade, magnetismo, óptica, mecânica e física térmica passaram a ser inter-relacionados e começaram a ser unificados (PURRINGTON, 1997, p.32). Por outro lado, diferentes interpretações da natureza também estavam simultaneamente vigentes: uma visão mecânica e utilitarista, influenciada pela revolução industrial na Inglaterra; uma visão idealista remanescente da revolução iluminista na Françaeuma visão romântica na Alemanha (CUNNIGHAM; JARDINE, 1990).

Visando a utilização de um estudo de caso histórico como estruturante de uma sequência didática baseada no ensino por investigação, este trabalho explora os experimentos realizados por Thomas Johann Seebeck (1770-1831) durante a primeira metade do século 19. A escolha por este episódio envolveu vários fatores. Um deles está associado a projeto anterior ${ }^{14}$ que desenvolvi em que

14 Trata-se de projeto desenvolvido no Edital Universal do CNPq de 2012 a 2015. Vários trabalhos decorrentes desse projeto podem ser encontrados em Silva e Guerra (2015). 
os temas eletricidade, magnetismo e calor foram trabalhados de maneira separada, tanto do ponto de vista histórico quanto experimental. Ao desenvolver esse projeto, observei que alguns estudos de casos históricos sobre esses temas tinham pontos em comum, como por exemplo a influência da Naturphilosophie. Outro aspecto comum era a adoção de entes imponderáveis na explicação de fenômenos, como eletricidade, magnetismo, flogisto e posteriormente o calórico. Tanto para os estudos de eletricidade e magnetismo, como aqueles associados ao calor, a atividade experimental assumia um papel preponderante para a compreensão da natureza e o estabelecimento de leis que explicavam seu funcionamento. Estes três fatores - a influência da Naturphilosophie, a presença de ente imponderável e a ênfase na atividade experimental - caracterizam o trabalho de Seebeck na obtenção da relação entre magnetismo e calor.

Outro aspecto que levou à escolha deste episódio está relacionado à distorção histórica quanto ao significado do "efeito Seebeck”. Em seu trabalho, Seebeck busca uma relação entre magnetismo e calor; porém o efeito Seebeck atualmente corresponde à relação entre eletricidade e calor (FERREIRA; SILVA, 2016; SILVA, 2019). O que teria levado a essa distorção? Seriam problemas na execução, na interpretação ou na divulgação do trabalho por Seebeck? Portanto, o episódio apresenta vários aspectos para serem explorados numa proposta didática usando a abordagem histórica e experimental, permitindo a discussão de aspectos científicos e metacientíficos.

Neste capítulo me restringirei aos estudos histórico e experimental realizados para aprofundamento do trabalho de Seebeck, indicando os caminhos que segui durante a pesquisa. Estes estudos foram desenvolvidos durante minha estadia na EuropaUniversität Flensburg, na Alemanha, em parceria com o grupo do Professor Peter Heering ${ }^{15}$. Ao final, indico alguns elementos

15 Participação como professor visitante no exterior, sob financiamento da CAPES (processo PVE Júnior 88881.172857/2018-01). 
que julgo serem importantes fazer parte da sequência didática. No entanto, tanto a elaboração como a execução da sequência serão feitos em momento posterior, pois dependem em grande parte da interação com docentes da Educação Básica e/ou Ensino Superior em atuação em sala de aula.

\section{Caminhos da pesquisa histórica}

Ao realizar a pesquisa histórica para utilização no Ensino deve-se considerar os limites do estudo de caso. Para este estudo, consideramos um período imediatamente anterior ao principal experimento de Seebeck (1821) e algum tempo após a publicação do trabalho, com a resposta da comunidade acadêmica. Neste item serão explicitados alguns elementos importantes para a elaboração da narrativa a ser utilizada numa sequência didática com abordagem histórica, problematizadora e contextualizadora. Como metodologia historiográfica serão adotados os pressupostos da moderna historiografia da ciência (KRAGH, 1987; ALFONSO-GOLDFARB; BELTRAN, 2004; MARTINS, L. 2005; MARTINS, 2012; 2014).

\section{Definindo objetivos}

O primeiro passo é definir adequadamente qual o objetivo, em sala de aula, com a abordagem histórica. Algumas opções são: 1) ilustrar a aula, 2) exemplificar um conteúdo, 3) discutir um conteúdo, 4) discutir a ciência e suas influências e implicações de um modo geral. Tais objetivos estão diretamente relacionados com o que se espera dos (as) alunos (as) após a aula. As opções 1 e 2 caracterizam mais uma exposição por parte do professor e que não requerem a interação com o aluno. Já as opções 3 e 4 implicam numa interação maior com o aluno, levantando perguntas, respostas e discussões. Em todas as opções, é importante que o material apresentado provenha 
de fontes fidedignas ou se perpetua um ciclo de reprodução de mitos. Portanto, as fontes são as mesmas, mas o que vai diferenciar o objetivo é a postura do professor e a forma como ele conduzirá a aula.

Para iniciar uma pesquisa histórica, uma sugestão é fazer perguntas sobre o assunto (MARTINS, 2005). Caso o objetivo da sequência seja o conteúdo, isso direcionará as perguntas a serem feitas para construir a narrativa. As perguntas deverão ter como resposta elementos que permitam explorar a questão do conteúdo. Exemplo: Por que Seebeck estava fazendo medidas de magnetismo e temperatura? Quais procedimentos ele utilizou em sua pesquisa? Que materiais, instrumentos, equipamentos, ele utilizou? O que ele já sabia sobre eletricidade, magnetismo e variação de temperatura?

Outras perguntas podem ajudar a entender o contexto em que ele escreveu o trabalho, já que isso está diretamente relacionado ao que ele já conhecia. Por exemplo: Que funções ele exercia quando realizou o experimento? Com quem trocava correspondência? Era um membro reconhecido social e academicamente? Que outros estudos estavam em destaque no período em que ele realizou e publicou seu trabalho? Qual foi a repercussão do seu trabalho?

As respostas para o primeiro grupo de perguntas podem ser encontradas na leitura do trabalho original de Seebeck e esclarecidas pelo "próprio cientista". O segundo grupo de perguntas implica em conhecer o entorno ao cientista, suas relações pessoais e se seu trabalho teve significado na sociedade da época. Para encontrar essas respostas, devem ser buscados os trabalhos de outros estudiosos do mesmo período (fontes primárias) e de historiadores que já trataram do tema (fontes secundárias). Com esse material, é possível construir o cenário em que Seebeck se encontrava e entender seu trabalho e o contexto. 


\section{Em busca das fontes primárias e secundárias}

Para construir o cenário é preciso saber quem é o personagem central: Thomas Seebeck (1770-1831). A biografia de um cientista contém dados pessoais e também pode indicar seus principais trabalhos e influências. Há dicionários de biografias científicas publicados ou disponíveis online que podem ser empregados como ponto de partida, mas que devem ser devidamente ponderados (COSTA, 2009). Também há catálogos ${ }^{16}$ que detalham toda a produção de alguns estudiosos do século 19 e que estão disponíveis para download. De posse da biografia e da lista de trabalhos, é necessário fazer uma busca para encontrar os trabalhos completos.

$\mathrm{Na}$ busca pelas fontes, é necessário lidar com o problema do idioma. Dependendo do tema, as fontes primárias podem estar em um idioma que o pesquisador não domina. Nesse caso, é recomendável trabalhar com o original e mais de uma versão traduzida, para o caso de possíveis erros de tradução; ou então mudar o tema. Trabalhar apenas com traduções pode levar a uma compreensão errada da obra original. Alguns trabalhos podem ser encontrados em source books, que são conjuntos de trabalhos parcial ou totalmente traduzidos para o inglês.

No caso de Seebeck, a biografia não se encontra nos dicionários de biografias científicas, mas foi possível encontrar uma biografia num artigo específico (VELMRE, 2007). A biografia não trouxe muita informação relevante, pois tratava-se de uma apologia com um relato anacrônico.

Seu trabalho está parcialmente traduzido para o inglês no Source Book in Physics (MAGIE, 1969) e a versão completa está disponível online (SEEBECK, 1825; 1895). A consulta a dois

16 Ver as indicações de Martins (2005) e Martins (2012). Alguns links importantes são: www.jstor.org; www.archive.org e https://gallica.bnf.fr. 
catálogos de obras (CATALOGUES, 1871; POGGENDORF, 1863) trouxe a mesma relação de trabalhos publicados por Seebeck - um total de 18 trabalhos, todos em alemão.

A princípio, esse material seria suficiente para responder às primeiras perguntas. No entanto, o relato de Seebeck deixava em aberto vários pontos e citava outros nomes. Nesse caso, é necessário buscar trabalhos de outros estudiosos, como aqueles que foram citados, para esclarecer melhor o assunto. Seebeck cita Schweigger, Weiss, Ørsted, Cumming. Qual a relação entre Seebeck e esses outros nomes? Ele também cita um trabalho anterior seu que o levou a fazer as medidas (SEEBECK, 1822). A leitura desse outro trabalho é importante para tentar entender o que ele pretendia no trabalho seguinte. Volta-se aos dicionários e catálogos para encontrar os elos.

Outra forma de tentar entender o que Seebeck não explica é buscar por trabalhos de outros historiadores que já estudaram esse tema. Nesse caso, recorre-se à base de dados que possuem periódicos sobre História da Ciência. Além da busca inicial no Google Scholar, outras bases importantes são a da History of Science Society (HSS) e a JSTOR ${ }^{17}$. Obras de outros historiadores podem esclarecer vários pontos e, com frequência, são mais acessíveis do que os originais. Mas podem apresentar uma visão tendenciosa e distorcer fatos, causas e consequências. Portanto não são aconselháveis como único material base para a construção da narrativa ${ }^{18}$. Há poucas fontes secundárias sobre Seebeck e várias sobre Hans Christian Ørsted (MARTINS, 1986; CANEVA, 1978; 1997) que citam Seebeck superficialmente, o que já indica que há uma relação entre os dois.

17 Links: https://hssonline.org/resources/hstm-database/ e www.jstor.org.

18 Martins (2005) e Martins (2014) discutem em detalhes a questão do "apudismo" e das correntes historiográficas que fornecem diferentes interpretações. 


\section{A parte experimental}

Este estudo de caso também envolve uma parte experimental que deve ser tratada com rigores historiográficos. Isto é, é preciso reproduzir o experimento de Seebeck da forma mais próxima possível ao modo como ele fez e buscar compreender seus procedimentos e resultados de maneira diacrônica.

Experimentos históricos envolvem conhecimentos conceituais, procedimentais e epistemológicos do ponto de vista do cientista. Ao se reproduzir um experimento ou instrumento histórico é preciso saber se o cientista poderia conhecer previamente a teoria envolvida no experimento, como ele manipulou seus equipamentos, quais dados considerou relevantes e porquê. Tudo isso imerso num contexto sociocultural que certamente influenciou em suas escolhas teóricas e procedimentais (SHAPIN, 1982).

Além de um conhecimento tácito na manipulação, descrições detalhadas de equipamentos e procedimentos, o trabalho experimental pode envolver ou não um conhecimento teórico prévio ou alguma concepção a priori $^{19}$ que acaba por direcionar o olhar do cientista para seus resultados (SHAPIN, 1982; STEINLE, 1997; 2002). Portanto, fontes primárias envolvendo experimentos às vezes só se tornam claras quando há a tentativa de reproduzir o experimento, o que pode exigir mais do que uma leitura atenta, já que a própria execução requer habilidades comuns ao experimentador em seu contexto. Como não é possível a reprodução igual ao original, seja pela inexistência de materiais ou pela descrição vaga do experimentador (FORS; PRINCIPE; SIBUM, 2016), a utilização de procedimentos ou equipamentos anacrônicos também pode levar a uma informação distorcida.

Durante o período em que Seebeck realizou seus trabalhos, a experimentação entre os estudiosos alemães era, em sua

19 Sugiro a leitura do capítulo de Roberto Martins neste livro sobre as concepções a priori no trabalho de Lavoisier. 
maioria, apenas qualitativa. Seebeck era reconhecido como um grande experimentador e a maior parte de seus trabalhos foi experimental. Mas ainda assim, não havia sistematização e acuidade em seu trabalho, o que era característico da época. Devido a essa concepção experimental, o relato do próprio Seebeck não fornece todos os detalhes experimentais necessários para a reprodução dos equipamentos e de seus procedimentos. Como consequência, a tentativa de reconstrução de seus experimentos apresentou vários desafios, desde encontrar os tipos de materiais usados, como também as respectivas medidas e o manuseio.

\section{Thomas Seebeck: biografia e principais trabalhos}

Na primeira metade do século 19, alguns estudiosos começaram a estabelecer interpretações comuns aos fenômenos envolvendo eletricidade, magnetismo e condução de calor. Para um dos programas de pesquisa que apontavam nessa direção, o comum nesses fenômenos era a existência de forças na natureza que tendiam a se manter em equilíbrio. Esse programa de pesquisa era bem representado pela Naturphilosophie e outra explicações filosóficas influenciadas por filósofos alemães, como Friedrich von Schelling (1775-1854) (CANEVA, 1997).

No caso dos seguidores da Naturphilosophie - como por exemplo Hans Christian Ørsted (1777-1851) e Johan Wilhelm Ritter (1776-1810) -, as forças responsáveis pelos fenômenos elétricos deveriam ser relacionadas às forças responsáveis pelos fenômenos magnéticos e de aquecimento (calor), uma vez que todas elas tinham como como origem a mesma força da natureza (CANEVA, 1997; SILVA; SILVA, 2017).

Foi sob influência da Naturphilosophie que Ørsted havia concluído sobre sua teoria eletromagnética em 1820, considerando que os efeitos magnéticos sobre a bússola eram causados pelo movimento do fluido elétrico em torno do fio. Os resultados 
de Ørsted assumiam um efeito magnético transversal ao fio, o que não foi aceito de imediato ${ }^{20}$. Em busca de verificar os resultados de Ørsted, vários estudiosos do período dedicaram-se em reproduzir e aperfeiçoar seu experimento. É neste cenário que Thomas Johann Seebeck fará suas contribuições: a influência da Naturphilosophie e da transformação das forças e a recente divulgação do trabalho de Orsted que apresentava uma relação entre eletricidade e magnetismo com uma simetria diferente da esperada.

\section{Biografia}

Thomas Johann Seebeck nasceu em Talin em 1770 e tornou-se médico em 1792 pela Universidade de Göttingen. Durante grande parte da sua vida foi um pesquisador independente, financiado pela herança deixada pelo seu pai, sem ter exercido a medicina (VELMRE, 2007). Entre 1802 e 1831 viveu em diferentes cidades com sua esposa e filhos, como Jena, Bayreuth, Nuremberg e Berlin, onde acabou falecendo em 1831. Durante sua estadia em Jena, tomou conhecimento das ideias da Naturphilosophie e estabeleceu contatos com Johann Wolfgang Goethe (1749-1832) e Christian Samuel Weiss (1780-1856), dois representantes da filosofia romântica da natureza. Pouco da sua vida pessoal é conhecido além do que está nas cartas trocadas com Goethe (NIELSEN, 1989), mas Seebeck teve dois filhos que tiveram destaque durante o século 19: Ludwig Friedrich Wilhelm August Seebeck (1805-1849), físico com vários trabalhos em acústica e Karl Julius Moritz Seebeck (1805-1884) pedagogo que contribui na reforma educacional alemã.

20 Os experimentos de Ørsted já foram explorados em vários trabalhos e não entrarei em detalhes aqui. Para mais informações sugiro Martins (1986a; 1986b) 
Entre 1806 e 1819 colaborou com Goethe em sua teoria das $\operatorname{cores}^{21}$, ficando responsável pela execução de experimentos que pudessem corroborar as ideias do poeta e naturfilósofo. No entanto, ao tornar-se membro da Academia de Ciências de Berlin em 1819, Seebeck interrompeu seu contato e colaboração com Goethe, já que sua teoria das cores não era bem-vinda entre os demais membros (NIELSEN, 1989). A amizade com Weiss permaneceu e foi de grande utilidade para seus experimentos, já que Weiss era o responsável pelo gabinete de minérios e forneceu o material necessário nos experimentos de Seebeck (SEEBECK, 1895, p.8).

Apesar de ser reconhecido como excelente experimentador e, por este fato ter sido admitido na Academia de Berlin, Seebeck não publicou muitos trabalhos (CATALOGUES, 1871; NIELSEN, 1989). Os dez artigos publicados entre 1806 e 1827 (sua última publicação) trataram de propriedades de minérios, reações químicas, polarização da luz e magnetismo. Em geral destaca-se a parte experimental, com a descrição das observações e fenômenos obtidos, mas não há proposições para explicar causas ou estabelecer padrões e teorias ${ }^{22}$, o que era comum para a época (NIELSEN, 1991).

\section{Principais trabalhos}

O trabalho em que Seebeck encontra a relação entre magnetismo e calor é o Magnetische Polarisation der Metalle und Erze durch Temperatur-Differenz, publicado nos Anais da Academia de Berlin de 1825 (Abhadlungen der physikalischen Klasse der

21 A teoria das cores de Goethe apresentava uma crítica a Newton. Para maiores informações sugiro Brito e Reis (2016).

22 Mesmo quando Seebeck tenta propor um modelo teórico, suas ideias são confusas e inconclusivas (NIELSEN, 1991; SILVA, 2019). 
Königlisch-Preußsischen). Os Anais de 1825 continham os trabalhos apresentados perante a Academia nos anos de 1822 e 1823. Devido a esse intervalo entre a realização e apresentação e a publicação do trabalho, Seebeck acaba trazendo no trabalho publicado resultados obtidos por outros estudiosos posteriormente à sua investigação ${ }^{23}$.

Ele inicia o trabalho mencionando o que o levou a realizar experimentos para investigar "que dois metais, conectados em círculo uns com os outros, eram magnéticos sem a participação de nenhum condutor úmido" (SEEBECK, 1895, p.4) foram os resultados que obteve em trabalho anterior. Sendo assim, conhecer esse trabalho anterior seria importante para entender os pressupostos de Seebeck. A seguir tratarei de alguns pontos principais desse trabalho e que possivelmente influenciaram as conclusões de Seebeck quanto ao termomagnetismo.

\section{Correntes galvânicas e magnetismo}

O trabalho que Seebeck menciona é o Über den Magnetismus der galvanischen Kette, apresentado perante a Academia de Berlin em 1820 e publicado em 1822 nos Anais da Academia. Nesse trabalho Seebeck realiza uma série de experimentos buscando compreender o que influencia na polarização magnética de um metal quando sujeito à eletricidade gerada por uma bateria galvânica. De modo geral, Seebeck está tentando se aprofundar no trabalho de Ørsted, e já parte de algumas considerações prévias quanto ao fenômeno observado, como a existência de polaridades elétrica e magnética, o que era parte das ideias da Naturphilosophie. Por exemplo, Seebeck assume que a bateria galvânica produz as polaridades elétricas $+E$ e $-E$, que são contrárias e que se anulam

23 Neste trabalho utilizei a versão de 1825 e também uma republicação de 1895, com anotações do editor, ambas em alemão. 
dentro da própria bateria. Portanto, não é apenas a eletricidade que gera a polarização magnética do fio.

Estes experimentos provam que existe uma polarização magnética peculiar na corrente galvânica fechada, independente de todas as influências externas, e que a mesma é invariável ao se inverter a posição dos polos elétricos da corrente (SEEBECK, 1822, p.293).

Variando as dimensões e materiais dos fios e a solução da bateria galvânica num circuito simples (Fig. 1), Seebeck encontra a distribuição da polarização magnética do circuito. Ele considera que o magnetismo, assim como a eletricidade, é polarizado em dois diferentes "estados", o $+m$ e $-m$, que se distribuem circularmente ao redor do fio (Fig. 2).

Fig. 1: Representação do circuito de acordo com a descrição e o desenho de Seebeck (1822, p.319). $Z$ e Cu representam as placas de zinco e cobre que constituem a bateria voltaica. $A$ e $B$ são fios de cobre. No interior de $A$ e $B$ há uma bússola. N é o norte magnético terrestre. Seebeck varia o diâmetro e o comprimento dos fios em $\mathrm{A}$ e $\mathrm{B}$ testando diferentes possibilidades.

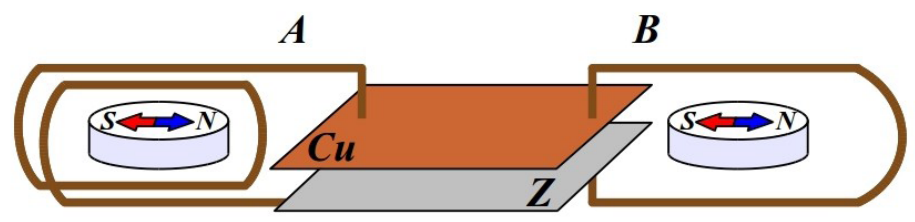

Fonte: Éwerton Jefferson Barbosa Ferreira (colaborador). 
Fig. 2: Corte transversal do circuito representado na Fig. 1, onde $A$ e $B$ representam os fios de cobre. Dispondo a bússola em diferentes posições em relação a $A$ e $B$, Seebeck determina a polaridade magnética $+\mathrm{m}$ e -m em relação à eletricidade nas espiras. Observa-se que a configuração da polaridade magnética em torno dos fios é circular.

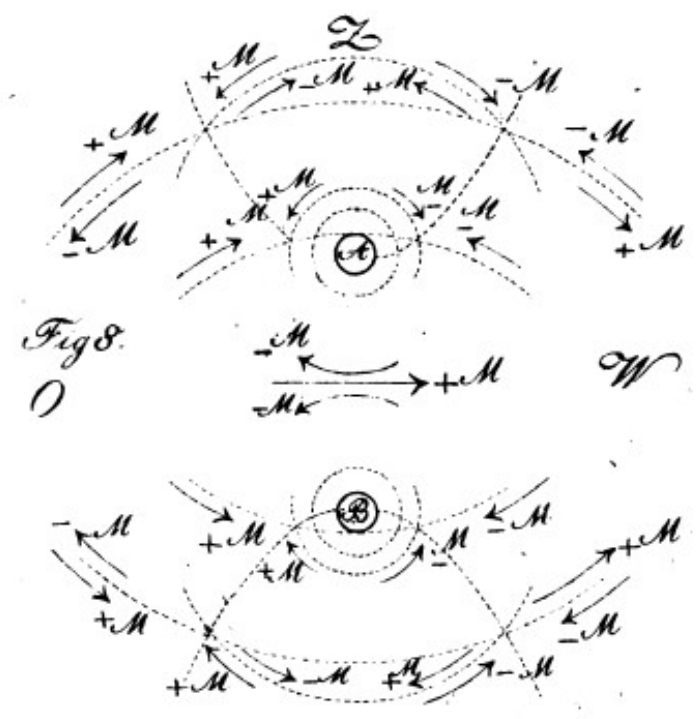

Fonte: Seebeck (1822).

Nas conclusões de Seebeck está claro que "polarização" é um conceito muito presente, que ele se alinha com Ørsted na configuração circular do magnetismo ao redor do fio, mas que não considera que o efeito magnético sobre a bússola é devido à eletricidade.

Ainda baseado no circuito da Fig. 1, Seebeck conclui que a deflexão da agulha magnética da bússola era proporcional ao comprimento dos fios. Em nota de rodapé ele acrescenta:

No entanto, nem todo aumento na temperatura do condutor que fecha a corrente galvânica causa um aumento do estresse magnético. 
Abaixo das hastes de metal, que eram colocadas brilhando nos suportes presos a uma corrente simples, o desvio da agulha magnética não era grande, mas não menor do que quando as hastes estavam frias. No entanto, o sucesso teria sido diferente se as hastes incandescentes tivessem acabado de tocar as placas de metal, como o ensaio a seguir mostrará com mais clareza (SEEBECK, 1822, p.325 - nota de rodapé).

Portanto, é nesta nota de rodapé que Seebeck apresenta uma possível relação entre magnetismo e calor. Uma vez que ele assumia que as polaridades elétricas eram anuladas no interior da bateria galvânica, atuavam apenas para ativar a polarização magnética existente no material (fio). Essa polarização magnética parecia estar associada a qualquer mudança no estado de coesão do material, já que ao aquecer o fio para soldar ao circuito também havia deflexão da agulha magnética.

A mudança ou dissimilaridade no estado de coesão deve, portanto, ser considerada como a condição mais essencial para a magnetização desses corpos (SEEBECK, 1822, p.334).

\section{Os experimentos que levaram ao termomagnetismo}

Baseado nos resultados anteriores, Seebeck propõe verificar se é possível produzir polarização magnética num metal sem usar a bateria galvânica. Uma vez que ele concluiu que a magnetização já está presente no material, submetendo esse material a outras situações que alteram seu estado de coesão, haveria uma polarização magnética, ou seja, apenas uma reorganização no sentido e direção da magnetização. Observemos como as experiências de Seebeck já estão sendo guiadas por conjecturas que preveem um possível resultado. 
Seguindo com os experimentos, ele monta um circuito sem a bateria galvânica. Neste circuito ele menciona um "multiplicador de Schweigger" feito com $12 \mathrm{~m}$ de uma fita de cobre de 0,5 $\mathrm{cm}$ de largura, 1 disco de cobre e 1 disco de bismuto. As dimensões dos discos não são informadas, tampouco a espessura da fita de cobre, o número de voltas ou a largura da espira.

Nesta montagem (Fig. 3), Seebeck pressiona com sua mão a fita de cobre contra o bismuto, que está sobre o disco de cobre, e observa uma deflexão da bússola (SEEBECK, 1895, p.5; FERREIRA; SILVA, 2016). Chamaremos este experimento de Experimento 1.

Fig. 3: Experimento 1 de Seebeck para investigar a relação entre calor e magnetismo. A espira (multiplicador de Schweigger) é de cobre (K). Ao final da espira ficam em contato um disco de cobre, bismuto (B) e a extremidade superior da espira. No interior da espira está uma bússola.

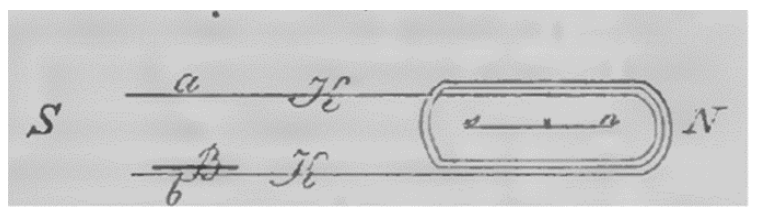

Fonte: Seebeck (1825).

Como a deflexão poderia estar associada a uma reação química entre os metais, usando a umidade da mão como condutora, Seebeck utiliza diferentes materiais para pressionar o conjunto cobre-bismuto-cobre. Ele usa madeira, outro metal e um papel umedecido. Em nenhum desses casos a deflexão ocorre. Usando novamente a mão, Seebeck verifica se a deflexão pode ocorrer com outros metais diferentes do bismuto. Ele substituiu o disco de bismuto por um de antimônio e obteve um desvio a leste. Outros metais como níquel, cobalto e urânio se comportaram como o 
bismuto; ferro, arsênio e telúrio, como o antimônio. Mas com um disco de zinco ou de prata, por exemplo, não houve deflexão.

A ausência de deflexão com o zinco eliminava a possibilidade de uma reação galvânica. A ausência de deflexão quando a mão é substituída por outros materiais eliminava a possibilidade de um fenômeno apenas mecânico. Como a tensão magnética deveria vir de uma mudança no "estado de coesão do metal", conforme resultados do trabalho anterior, Seebeck concluiu que era o calor transferido pela mão que causava o magnetismo (SEEBECK, 1895, p.9).

Esta conclusão leva Seebeck a realizar outros experimentos para confirmar que era o calor que provocava a polarização magnética do metal. Para isso ele faz montagens semelhantes a circuitos usando junções de dois metais diferentes, começando com bismuto-cobre e antimônio-cobre (Fig. 4). Nas extremidades das junções a temperatura era modificada utilizando-se uma fonte de calor. A agulha magnética da bússola localizada no meio do circuito identificava a variação magnética, sendo que a deflexão tinha sentido contrário para o bismuto e para o antimônio.

Fig. 4: Experimentos com uma espira de cobre e uma barra de bismuto (acima) ou antimônio (abaixo). $\mathrm{Na}$ extremidade inferior (b warm) as barras são aquecidas com uma vela.

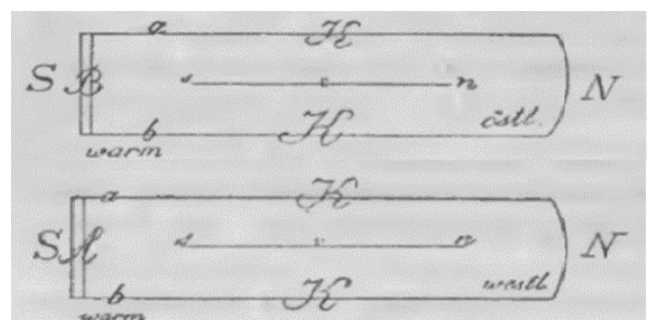

Fonte: Seebeck (1825). 
Ele verificou que não era o calor que provocava a deflexão da agulha, mas uma diferença de temperatura entre os pontos de contato das combinações metálicas. Quando as duas extremidades estavam a mesma temperatura, seja por aquecimento ou por resfriamento; ou quando a barra era aquecida no meio, havia a modificação na "coesão do metal", mas o magnetismo permanecia latente. Apenas com a diferença de temperatura entre as extremidades é que se produzia tensão magnética. Seebeck conclui:

De todos esses experimentos podemos concluir que a primeira e mais importante condição para o aparecimento do magnetismo livre nesse circuito metálico é a diferença de temperatura nos pontos de contato dos dois elementos. Sem dúvidas o magnetismo também será provocado se ambos os pontos de contato dos metais ou minérios são aquecidos ao mesmo tempo e a um mesmo grau; não haverá nenhuma ação na agulha magnética, no entanto, neste caso, porque através deste procedimento uma dupla e oposta polarização magnética será provocada no circuito, e é em toda parte de igual força (SEEBECK, 1895, p.11).

Seebeck então fez circuitos termomagnéticos utilizando barras de diferentes comprimentos para verificar como se dava a variação da intensidade da deflexão de acordo com o comprimento (Fig. 5). Para isso, ele conectou barras de cobre e de bismuto e antimônio, variou a temperaturas nas extremidades onde havia contato entre os metais e verificou a deflexão da bússola (SEEBECK, 1895, p.15; FERREIRA; SILVA, 2016). Com os resultados, ele fez uma tabela reordenando as combinações de metais como "mais a Oeste" ou "mais a Leste", de forma totalmente fenomenológica (SEEBECK, 1895; SILVA, 2019). 
Fig. 5: Circuitos termomagnéticos. De cima para baixo: bismutocobre; antimônio-bismuto (em série)-cobre; antimônio-bismuto (em paralelo)-cobre.
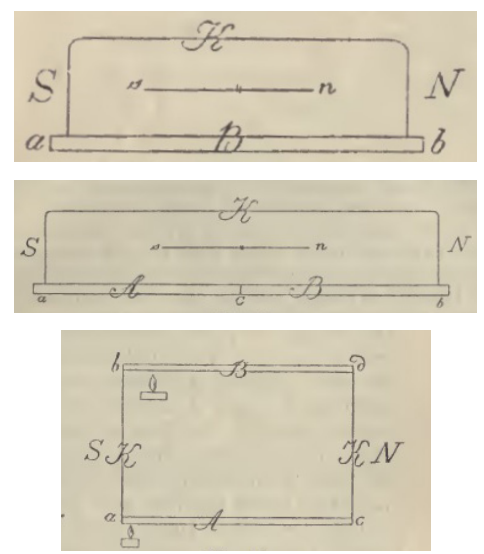

Fonte: Seebeck (1825).

De forma totalmente qualitativa e fenomenológica, Seebeck conclui que: (i) deve haver uma diferença de temperatura entre os pontos de contato para que haja tensão magnética; (ii) a intensidade da tensão magnética no circuito termomagnético é proporcional à diferença de temperatura; (iii) a configuração do magnetismo em circuitos termomagnéticos é a mesma que em circuitos elétricos e; (iv) a intensidade da tensão magnética é inversamente proporcional ao comprimento dos condutores (SEEBECK, 1825; 1895). Com exceção de alguns resultados iniciais (primeiro experimento), Seebeck não fornece os valores de deflexão da bússola (ângulo), nem valores para as temperaturas. Ele também menciona que o aquecimento e resfriamento dos metais poderia alterar sua estrutura interna e causar modificações na magnetização, mas não esclarece de que forma isso ocorreria (SEEBECK, 1895, p.78). 
Ao final do trabalho, Seebeck apresenta considerações sobre como o presente estudo poderia servir para explicar o magnetismo terrestre, uma vez que se supunha que o interior da Terra possuía muitos metais sujeitos a diferentes temperaturas devido à posição em relação ao Sol (SEEBECK, 1895, p.112).

Há várias considerações a serem feitas sobre os experimentos, procedimentos e resultados de Seebeck que deveriam ter provocado uma reação na comunidade científica da época questionando-o (SILVA, 2019). No entanto, quando este trabalho foi publicado, apenas serviu como uma complementação ao que Ørsted já havia divulgado em 1823 (ØRSTED, 1823) e não há trabalhos que o questionem; também não há nenhum novo trabalho de Seebeck complementando ou esclarecendo suas ideias.

Por volta de março de 1823 Ørsted havia visitado Seebeck, para saber o que estava sendo feito a partir dos resultados de sua teoria eletromagnética. Ele considerou que os circuitos termomagnéticos de Seebeck eram, na verdade, termoelétricos, em que o calor assumia o mesmo papel do líquido no circuito galvânico.

Como escrevi alguns dias atrás, fiz uma interessante descoberta, a saber, de um aparato galvânico que consiste somente de materiais sólidos sem a mediação de qualquer líquido. (...) Com a ajuda das minhas descobertas eletromagnéticas, Seebeck em Berlim chegou a mais bonita das descobertas que surgiu da minha, especificamente que se alguém monta um anel de dois pedaços curvos feitos de diferentes metais e aquece uma das junções, o anel inteiro tem o mesmo efeito sobre a agulha da bússola como um circuito galvânico. Os dois metais que fornecem melhor efeito neste experimento são o bismuto e o antimônio. Um pedaço destes dois metais soldados juntos tem o mesmo efeito que zinco e cobre num circuito 
galvânico. E eu ouso dizer que, desta forma, o calor tem o efeito do líquido (carta de Ørsted a sua esposa - JELVED; JACKSON, 2011, p.340).

Ørsted não menciona nada sobre o Experimento 1. Ele apenas utilizou os resultados dos circuitos termomagnéticos para corroborar sua própria teoria eletromagnética (CANEVA, 2007; SILVA, 2019).

Apesar dos resultados dos circuitos termomagnéticos terem mais destaque após a publicação de $\varnothing_{\text {rsted }^{24}}$, considero que o Experimento 1 é fundamental para entender os pressupostos de Seebeck. Afinal, segundo seu relato, se este experimento não indicasse uma relação entre o calor da mão e a deflexão da agulha magnética, ele não teria dado andamento aos demais experimentos que serviram para confirmar sua hipótese inicial. Por este motivo, darei detalhes da sua reprodução.

\section{A reprodução do Experimento 1}

Ao tentar reproduzir o Experimento, a primeira dificuldade se deu quanto ao "multiplicador". A imagem que Seebeck apresenta difere consideravelmente do multiplicador que Schweigger propôs em 1821 (Fig. 6) e também do instrumento divulgado por Ørsted (Fig. 7).

24 Ver, por exemplo, as considerações de Ørsted para a criação de uma pilha termoelétrica (SILVA, 2019). 
Fig. 6: Uma das propostas de multiplicador de Schweigger. Vários fios de cobre enrolados de maneira sobreposta. Schweigger não menciona a necessidade de isolamento entre um fio e outro, nem a quantidade de espiras necessárias.

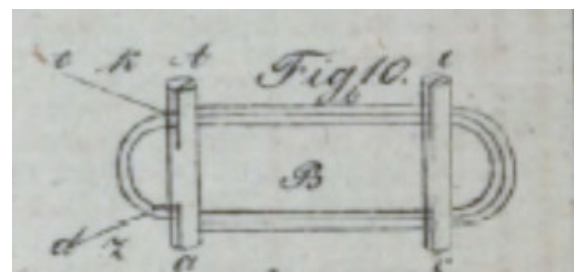

Fonte: Schweigger (1821).

Fig. 7: Representação de Ørsted para o multiplicador de Schweigger, sem alterar seus "aspectos essenciais", segundo o autor. Várias voltas do fio de cobre em torno do suporte B. No meio dos fios há um orifício pelo qual a agulha magnética fica suspensa entre as espiras.

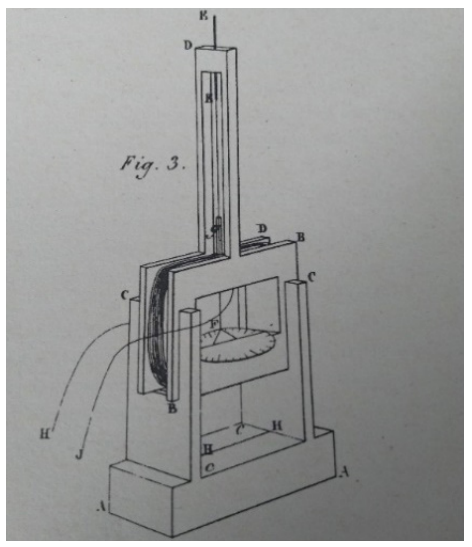

Fonte: Ørsted (1823a, p.437).

Os dois multiplicadores utilizam fios de cobre. Em nenhum deles é mencionada a quantidade de voltas, o comprimento e 
diâmetro do fio ou algum isolamento entre as voltas. No instrumento divulgado por Ørsted a bússola está suspensa. Como a figura de Seebeck não se assemelhava aos outros multiplicadores conhecidos (CHIPMAN, 1966), busquei em seu trabalho outro experimento em que ele o tivesse utilizado.

Encontrei menção ao multiplicador de Schweigger com as mesmas dimensões em uma das variações do experimento da Fig. 1 (SEEBECK, 1822, p.319). Em nota de rodapé, Seebeck acrescenta que as voltas da fita de cobre foram isoladas usando seda. Há também menção à bússola usada nos experimentos, a qual seria "de bolso" 25 e com uma agulha magnética de $6 \mathrm{~cm}$, o que me levou a concluir que cada volta, aproximadamente retangular pelo desenho da Fig. 3, tinha, aproximadamente, $8 \mathrm{~cm}$ de lado por 4 $\mathrm{cm}$ de altura (considerando $2 \mathrm{~cm}$ de altura da bússola e as proporções do desenho). Considerando a fita de $12 \mathrm{~m}$, isso daria cerca de 50 voltas! Porém, não foi possível encontrar $12 \mathrm{~m}$ de fita de cobre contínua e qualquer emenda aumentaria a resistência do circuito. Ele não menciona a espessura, o que seria fundamental para determinar a flexibilidade da fita para fazer as voltas necessárias e também para ter uma estimativa do tamanho do multiplicador. Por exemplo, se a fita possuísse uma espessura de $0,5 \mathrm{~mm}$, cada lado do multiplicador teria $2,5 \mathrm{~cm}$ de largura.

Com uma fita de $1 \mathrm{~mm}$ de espessura, $1 \mathrm{~m}$ de comprimento e $5 \mathrm{~mm}$ de largura, foi possível fazer 3 voltas, usando uma agulha magnética de $3 \mathrm{~cm}$. As voltas foram encapadas com seda 100\%, e o conjunto de espiras foi enrolado com linha de linho para que ficassem superpostas. A montagem que fiz (Fig. 6) baseada apenas nas informações obtidas nos textos se assemelha muito à figura que Seebeck fez (Fig. 3).

25 Se a bússola é "de bolso", não se enquadra no modelo de Ørsted de agulha suspensa. 
Fig. 6: Montagem aproximada do Experimento 1. O suporte de plástico para a bússola apenas serviu como apoio, já que não foi possível entender exatamente, pelo relato de Seebeck, como a bússola se equilibrava sobre o multiplicador.

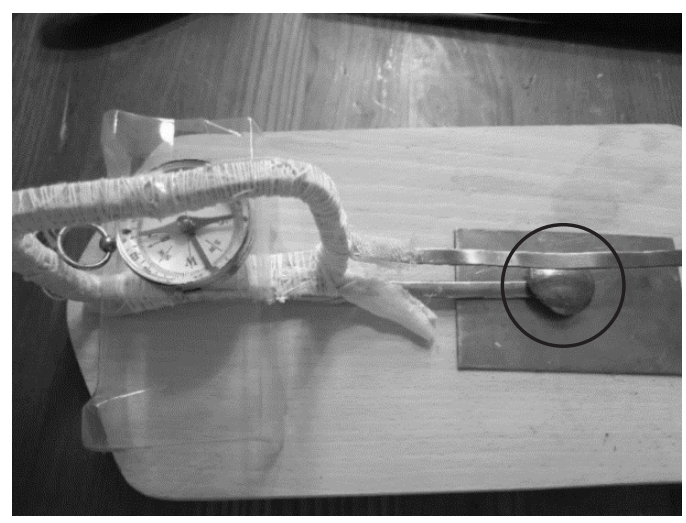

Fonte: a autora.

Assim, considerando apenas as informações descritas por Seebeck, pressionando a fita de cobre sobre o disco de bismuto com a minha mão, seria possível observar uma deflexão na agulha magnética. Isto não aconteceu. Algumas variáveis que não estavam bem detalhadas por Seebeck poderiam estar afetando os resultados, como: a temperatura do meu corpo em relação à temperatura ambiente (de quantos graus deveria ser a diferença?); a espessura da fita; a espessura do disco de bismuto; a área de contato entre a fita e o disco e o número de voltas da fita (o efeito seria muito pequeno para ser identificado?).

Estas variáveis foram consideradas nas próximas tentativas. Assim, o que fiz foi: reduzir a espessura da fita (desbastando-a com uma lixa) na região de contato com o disco de bismuto; reduzir a espessura do disco de bismuto e aumentar a região de contato deixando-o bem plano e reduzir o tamanho das espiras. Cada uma dessas mudanças foi feita separadamente para identificar o quanto 
afetava os resultados, ou melhor, levava a uma deflexão de agulha. A configuração final da montagem, após todas essas mudanças corresponde à Fig. 7 .

Fig. 7: Segunda montagem experimental, baseada nos relatos de Seebeck e nas variáveis identificadas. Observe que a espessura da fita no contato com o bismuto é mais fina e que também o disco de bismuto é mais fino. Usando o mesmo comprimento da fita de cobre para fazer o multiplicador, mas considerando dimensões menores, foi possível incluir duas voltas a mais, mas a agulha magnética é menor.

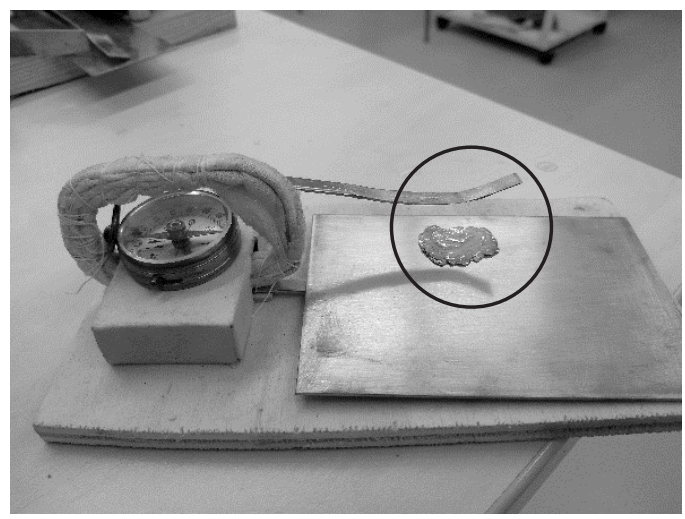

Fonte: a autora.

O destaque nas duas figuras (Fig. 6 e Fig. 7) mostra a diferença na espessura da fita no ponto de contato. O bismuto é extremamente maleável e sob aquecimento de uma vela já começa a derreter. O novo disco usado possuía menos de $1 \mathrm{~mm}$ de espessura. Para fazer o multiplicador ainda considerei apenas $1 \mathrm{~m}$ de fita de cobre, mas com o novo tamanho foi possível fazer mais duas voltas, totalizando 5 voltas. Nesta nova configuração ainda não foi possível identificar a deflexão da agulha apenas usando a mão. Portanto, a variável relativa à diferença de temperatura necessária era fundamental. 
Se a fita era aquecida com a chama de uma vela na região de contato com o bismuto, a deflexão ocorria, mas diminuía de intensidade numa segunda tentativa. Uma possível explicação para isso era a presença de fuligem na região de contato. Por este motivo, os contatos cobre-bismuto-cobre eram lixados após cada tentativa, o que ficava inviável quando a fita era aquecida com a vela.

A ausência de deflexão com a mão à temperatura ambiente e a deflexão com o aquecimento pela vela levou a um meio termo de diferença de temperatura que poderia ocasionar a deflexão. Como todo o conjunto experimental estava a temperatura ambiente $\mathrm{e}$ a temperatura ambiente estava próxima à temperatura corporal, utilizei um copo de água quente para aquecer minha mão antes de pressionar a fita.

Com a mão aquecida em torno do copo de água fervente, pressionei a fita sobre o fino disco de bismuto e a agulba defletiu! A agulha permanecia defletida até que o dedo e a fita ficassem em equilibrio térmico, o que era relativamente rápido já que a diferença de temperatura não era alta e a fita estava bem fina, com rápida condução de calor.

Porém, diferente da descrição feita por Seebeck, a deflexão só ocorreu porque foram tomadas uma série de providências visando esse objetivo, como: uma fina fita de cobre, fino disco de cobre, ampla região de contato, limpeza do contato para evitar a oxidação e, talvez o mais importante, uma diferença de temperatura considerável entre o ambiente e a mão. Ou seja, eu estava esperando que o calor provocasse uma deflexão. O que nos leva a questionamentos como: teria Seebeck se atentado para as condições necessárias para que houvesse algum efeito? Se não houvesse deflexão da agulha na primeira tentativa, ele atribuiria o resultado a um erro na sua hipóteseou a problemas no experimento?

Estas questões não podem ser respondidas, pois fazem parte da complexidade de se trabalhar com experimentos históricos. 
Conforme mencionei no início do texto, a descrição de experimentos, principalmente aqueles que não estão muito sistematizados como é o caso de Seebeck, não é suficiente para compreender as intenções do experimentador.

\section{Elementos para uma sequência didática}

Para elaborar uma sequência didática com a abordagem histórica, vale a pena perguntar: em que o presente episódio pode colaborar para o ensino de ciências? Do meu ponto de vista, os objetivos 1) e 2) do item 2.1 não contribuem efetivamente para promover a discussão de temas científicos ou metacientíficos. Podem contribuir para o interesse dos alunos, mas não permitem ampliar qualquer discussão, já que acabam por apresentar uma ciência que "deu certo", tornando o ensino a mera reprodução de fatos (ROBILOTTA, 1988). Assim sendo, o presente episódio histórico poderia contribuir para ampliar discussões sobre o conceito - a relação entre calor, magnetismo e eletricidade; sobre as influências sobre o trabalho científico e como a divulgação de resultados pode ser tendenciosa para atender a interesses pessoais - como Ørsted fez para validar sua própria teoria.

No caso de discutir o efeito Seebeck do ponto de vista do conteúdo, é possível enfatizar as propriedades da matéria, a diferença entre um fenômeno elétrico e magnético eas relações existentes entre eles e o conceito de calor (como "energia em trânsito"). Considero como necessário, na sequência didática, que haja um conhecimento prévio sobre os experimentos e pressupostos de Ørsted (preferencialmente do ponto de vista histórico, para salientar a influência da concepção filosófica da Naturphilosophie); uma introdução a fenômenos do cotidiano em que fenômenos relacionando eletricidade, calor e magnetismo estejam presentes (por exemplo, um termopar ou termômetro digital); a introdução de problemas experimentais ou teóricos de solução aberta, como, 
por exemplo, a reprodução didática do Experimento 1 de Seebeck e a introdução de uma narrativa histórica que enfatize os aspectos controversos e ambíguos dos procedimentos e resultados experimentais de Seebeck.

É óbvio que qualquer sequência didática deve ser flexível tanto na metodologia de ensino quanto aos requisitos dos alunos, adequando-se a diferentes públicos e situações didáticas. Portanto, tanto a narrativa histórica quanto as atividades a serem propostas só podem ser planejadas e avaliadas na medida em que forem implementadas, numa discussão conjunta entre professores - que implementam - e pesquisadores - que propõem.

É nesse ambiente de interação entre professores, pesquisadores e alunos que o Grupo de História da Ciência e Ensino da Universidade Estadual da Paraíba (GHCEN) vem contribuindo para a inserção da abordagem histórica e experimental em sala de aula da Educação Básica e do Ensino superior. O Grupo concentra seus esforços na formação inicial de professores, buscando capacitá-los para a utilização da abordagem histórica para contextualizar, de forma problematizadora, o ensino de ciências em diferentes níveis de escolaridade (PINTO; SILVA; FERREIRA, 2017; PINTO; SILVA; PINTO, 2018).

\section{Considerações finais}

A reprodução do Experimento 1 de Seebeck mostrou que uma fonte primária sobre atividades experimentais pode conter várias omissões fundamentais para a compreensão dos pressupostos e resultados do cientista. Tais omissões só se tornam explícitas à medida que a reprodução é realizada, incluindo não somente especificidades quanto aos materiais e objetos utilizados, como também aos procedimentos e habilidades técnicas do contexto histórico que são essenciais no manuseio de equipamentos e sua interpretação. Além disso, o estudo das fontes primárias associadas 
ao termomagnetismo trouxe à tona aspectos metacientíficos que permitem explorar controvérsias e influências na ciência.

Quanto à utilização do presente estudo de caso histórico no ensino de ciências, sua adaptação depende de múltiplas variáveis, satisfeitas a partir de uma ampla interação entre professores e pesquisadores, na busca por um ensino contextualizado e problematizador, como sugerem as pesquisas e os documentos educacionais.

Uma questão que vale a pena salientar na presente discussão é que o assunto "efeito Seebeck" aparece apenas no Ensino Superior. Do ponto de vista conceitual, a compreensão do fenômeno implica em uma discussão sobre semicondutores e movimento de portadores positivos e negativos no interior do metal. Porém, como vimos na discussão de Seebeck, a compreensão do fenômeno não está diretamente relacionada à compreensão de sua natureza. Quando Seebeck associou os efeitos magnéticos à diferença de temperatura, ele ainda assumia magnetismo (com duas polaridades) e o calor (calórico) como fluidos. Portanto, pergunto-me - e acredito que seja interessante questionar os alunos também - por que assumimos como certo (efeito Seebeck) algo que foi construído sobre conceitos que consideramos, atualmente, ultrapassados?

Somente a história da ciência pode proporcionar tais questionamentos, embora nem sempre seja seu papel respondê-los.

\section{Referências}

ALFONSO-GOLDFARB, Ana Maria; BELTRAN, Maria Helena Roxo. Escrevendo a história da ciência: tendências, propostas e discussões historiográficas. São Paulo: Editora Livraria da Física, 2004. 
BRITO, Nathaly Barboza; REIS, José Claudio de Oliveira. A teoria das cores de Goethe e sua crítica a Newton. Revista Brasileira de História da ciência, v.9, n.2, p.288-298, 2016.

CACHAPUZ, Antônio; GIL-PEREZ, Daniel; CARVALHO, Anna Maria Pessoa; PRAIA, João; VILCHES, Amparo (orgs.). A necessária renovação do ensino das ciências. 2. ed. São Paulo: Cortez, 2011.

CANEVA, Kenneth L. From galvanism to electrodynamics: the transformation of German Physics and its social context. Historical Studies in the Physical Sciences, v.9, p.63-159, 1978.

CANEVA, Kenneth L. Oersted's presentation of others' - and his own - work. In: BRAIN, Robert M.; COHEN, Robert S.; KNUDSEN, Ole (eds.). Hans Christian Ørsted and the Romantic Legacy in Science: Ideas, Disciplines, Practices, New York: Springer, 2007, p.273-338.

CANEVA, Kenneth L. Physics and Naturphilosophie: a reconnaissance. History of science, v.35, n.1, p.35-106, 1997.

CARVALHO, Anna Maria Pessoa. O ensino de ciências e a proposição de sequências de ensino investigativas. In: CARVALHO, Anna Maria Pessoa (org.) Ensino de ciências por investigação: condições para implementação em salas de aula. São Paulo: Cengage Learning, 2013, p.1-20.

CATALOGUE OF SCIENTIFIC PAPERS (1800-1863). Compiled and published by the Royal Society of London. v. V. London, 1871, p.620. 
CHIPMAN, Robert A. The earliest electromagnetic instruments. Bulletin Smithsonian Institution, United States National Museum. Smithsonian Press, n.240, p.123-136, 1966.

COSTA, Felipe A. P. L. Dicionário de biografias científicas. Cadernos de Saúde Pública, v.25, n.3, p.704-705, 2009.

CUNNIGHAM, Andrew; JARDINE, Nicholas. (Ed.). Romanticism and the sciences. Cambridge: Cambridge University, 1990.

FERREIRA, Ewerton J. Barbosa; SILVA, Ana Paula Bispo. Termomagnetismo ou termoeletricidade? Um estudo do trabalho de Thomas Johan Seebeck. Caderno Brasileiro de Ensino de Física, v.33, p.861-878, 2016.

FORS, Hjalmar; PRINCIPE, Lawrence M.; SIBUM, H. Otto. From the library to the laboratory and back again: experiment as a tool for historians of science. AMBIX, v.63, n.2, p.85-97, 2016.

HEERING, Peter; HÖTTECKE, Dietmar. Historicalinvestigative approaches in science teaching. In: International handbook of research in history, philosophy and science teaching. Springer, Dordrecht, 2014, p.1473-1502.

HÖTTECKE, Dietmar; SILVA, Cibelle Celestino. Why implementing history and philosophy in school science education is a challenge: An analysis of obstacles. Science \&Education, v.20, n.3-4, p.293-316, 2011.

JARDIM, Wagner Tadeu; GUERRA, Andreia. República das Letras, Academias e Sociedades Científicas no século XVIII: a 
garrafa de Leiden e a ciência no ensino. Caderno Brasileiro de Ensino de Física, v.34, n.3, p.774-797, 2017.

JELVED, Karen; JACKSON, Andrew D. The travellettersof HC Ørsted. Det Kongelige Danske Videnskabernes Selskab, 2011.

KRAGH, Helge. An introduction to the historiography of science. Cambridge: Cambridge U.P., 1987.

MAGIE, William F. A source book in physics. Cambridge, MA: Harvard Univ. Press (10th reprint.), 1969.

MARTINS, Lilian A. Pereira História da ciência: objetos, métodos e problemas. Ciência \& Educação, v.11, n.2, p.305-317, 2005.

MARTINS, Roberto de Andrade. Oersted e a descoberta do eletromagnetismo. Cadernos de História e Filosofia da Ciência, v.10, p.89-114, 1986.

MARTINS, Roberto de Andrade. Experiências sobre o efeito do conflito elétrico sobre a agulha magnética. Cadernos de História e Filosofia da Ciência, v.10, p.115-122, 1986a.

MARTINS, Roberto de Andrade. DragomirHurmuzescu e o estabelecimento da magnetoquímica no final do século XIX. In: Silva, C. C.; Salvatico, L. (eds.) Filosofia e História da Ciência no Cone Sul. Seleção de trabalhos do 7o. Encontro da AFHIC. Porto Alegre: Entrementes Editorial, 2012, p.492-501.

MARTINS, Roberto de Andrade. O rinoceronte de Dürer e suas lições para a historiografia da ciência. Filosofia e História da Biologia, v.9, n.2, p.199-238, 2014. 
NIELSEN, Keld. Another kind of light: the work of TJ Seebeck and his collaboration with Goethe. Part I. Historical studies in the physical and biological sciences, v.20, n.1, p.107-178, 1989.

NIELSEN, Keld. Another kind of light: the work of TJ Seebeck and his collaboration with Goethe, Part 2. Historical studies in the physical and biological sciences, v.21, n.2, p.317-397, 1991.

ØRSTED, Hans C. New experiments by Dr. Seebeck on electromagnetic effects. Annales de chimie et de physique. v.22, p.199-201, 1823.

ØRSTED, Hans C. On M. Schweigger's electromagnetic multiplier, with an account of some experiments made with it. AnnalsofPhilosophy, v.5, p.436-439, 1823 a.

PINTO, Ingrid K. L. Santos; SILVA, Ana Paula Bispo; PINTO, José Antônio F. Entre o planejamento e a execução: desafiso de uma abordagem histórica para ensinar eletrostática. Experiências em Ensino de Ciências, v.13, n.4, p.192-211, 2018.

PINTO, José Antônio F.; SILVA, Ana Paula Bispo; FERREIRA, Ewerton J. Barbosa. Laboratório desafiador e história da ciência: um relato de experiência com o experimento de Oersted. Caderno Brasileiro de Ensino de Física. , v.34, p.176-196, 2017.

POGGENDORFF, Johann. C. Biographisch-literarisches Handwörterbuch zu Geschichte der Exacten Wissenchaften.

Leipzig: Verlag von Johann Ambrosius Barth, 1863. p.890.

PURRINGTON, Robert D. Physics in the nineteenth century. London: Rutgers University Press, 1997. 
ROBILOTTA, Manoel Roberto. O cinza, o branco e o preto-da relevância da história da ciência no ensino da física. Caderno Brasileiro de Ensino de Física, v. 5, p. 7-22, 1988.

SCHWEIGGER, Johann S. C. Zusätzezu Oersteds elektromagnetischen Versuchen. Journal fürChemie und Physik, Band I, Heft 4, p.1-17, 1821

SEEBECK, Thomas J. Magnetische Polarisation der Metalle und Erze durch Temperatur-Differenz (1822-1823). Ostwald's Klassiker der Exakten Wissenschaften. No. 70. Leipzig: Wilhelm Engelmann, 1895.

SEEBECK, Thomas J. Magnetische Polarisation der Metalle und Erze durch Temperatur-Differenz. Abhadlungen der physikalischen Klasse der Königlisch-Preußsischen. Akademie der Wissenschaftten aus den Jahren 1822-1823. Berlin: 1825, p.265 -373.

SEEBECK, Thomas. J. Über den Magnetismus der galvanischen Kette. Abhadlungen der physikalischen Klasse der KöniglischPreußsischen. Akademie der Wissenschaftten aus den Jahren 1820-1821. Berlin: 1822, p.289-346.

SHAPIN, Steven. History of science and its sociological reconstructions. History of Science, v.20, n.3, p.157-211, 1982.

SILVA, Ana Paula Bispo. Distorções científicas perenes e suas consequências para o ensino de ciências: a relação entre eletricidade, magnetismo e calor. Revista Brasileira de Ensino de Física, v.41, n. 4, e20180311, 2019.

SILVA, Ana Paula Bispo; GUERRA, Andreia (orgs.). História da ciência e ensino: fontes primárias e propostas para a sala de aula. Coleção Contextos da Ciência. São Paulo: Livraria da Física, 2015. 
SILVA, Ana Paula Bispo; SILVA, Jamily Alves. A influência da Naturphilosophie nas ciências do século XIX: eletromagnetismo e energia. História, Ciências, Saúde-Manguinhos, v.24, n.3, p.687$705,2017$.

STEINLE, Friedrich. Entering new fields: exploratory uses of experimentation. Philosophy of Science, v.64, p. S65-S74, 1997.

STEINLE, Friedrich. Experiments in history and philosophy of science. Perspectives on science, v.10, n.4, p.408-432, 2002.

VELMRE, Enn. Thomas Johann Seebeck (1770-1831). Estonian Journal of Engineering, v.13, n.4, p.276-282, 2007. 